\title{
Webfolio: An online learning community to help link university studies and classroom practice in preservice teacher education
}

Reesa Sorin

James Cook University

The Webfolio project was developed at James Cook University to extend students' professional learning beyond what is taught in lectures or gleaned through the practicum. Through web based case studies, early childhood and primary preservice teachers explored topics of professional significance to their growth as teachers. Each case study included a range of media, such as: work samples; audiotaped conversations; links to websites; telephone and in person professional opinions from practising teachers, principals, social workers and welfare agents; and online discussion with other participants, including students, teachers and university lecturers.

Case studies were based on authentic classroom situations; ones which student teachers may never encounter during their practicums, therefore requiring them to immerse themselves in the professional world of teaching into which they were moving. There were no single, correct solutions; rather learners were encouraged to reflect, imagine and develop multiple and often non-traditional solutions. This exploration was supported within a learning community, where participants were positioned as co-learners, scaffolding each other's learning while building links to the professional world. These links may assist in bridging the gap that some neophyte teachers feel when beginning their professional teaching careers.

\section{Introduction}

Current early childhood and primary teacher training comprises four years of academic study and up to 100 days of practicum in educational settings. When students complete these requirements, they become eligible for registration as a teacher and usually move directly into employment. They will have had four years of disparate subject offerings, where lecturers target a number of generic skills and topics. Preservice teachers may have limited, if any, experience with a number of issues that teachers in classrooms may face in their day to day routine, such as bullying, child 
protection and ethics; and few opportunities to collaborate and build networks with other preservice teachers, lecturers, teachers or educational support personnel. Student teachers often report a lack of connection between what is learned in university studies and in the classroom, and often report feeling unprepared for the "real life" situations that face them in their first days of classroom teaching (Sorin, 2002). Carol, a third year education student who participated in the Webfolio trial, noted: "As much as our Bachelor of Education course is comprehensive and in depth, it cannot hope to expose us to the myriad of emotive and contentious issues we will no doubt be exposed to even within the first few years of our teaching career."

University teaching, for the large part, occurs in lecture theatres that seat from 70 to 250 students, and transmission style lecturing may be the dominant mode of subject delivery. While we as lecturers pay lip service to alternative approaches, such as authentic, problem based learning and collaboration, we seldom model these approaches. Modelling is an effective and necessary component in teacher education, as students are more likely to incorporate and use models they see and experience in university practice in their own teaching (Kluth and Straut, 2003).

We also need to change the way topics are developed, taught and learned, through identifying and examining significant professional issues in an integrated, cross-curricular way that incorporates different disciplinary approaches. For example, an issue such as child protection could cross over child development subjects, care and service subjects and teaching methods subjects, and so could be explored by each area in turn or by a team approach to subject delivery.

Teaching and learning teams should not be limited to one or a group of lecturers and students, but should aim for a broader collaboration (Baskin and Anderson, 2003) with the education community, including classroom teachers, school guidance counsellors, social workers, and health, safety and welfare officers. "With greater collaboration, opportunities exist for team members to express their views and respond to each other's ideas, thus allowing them to construct new ideas" (Damoense, 2003, p.28). This would build professional networks that help to bridge the gap between university studies and professional practice (Sorin, 2002). It would also help to develop a community of learners, where students learn from other students and from professionals, and professionals also learn and enrich their practice. According to Lave and Wenger (1991), novices must have access to arenas of mature practice and must become a part of the community. 
Finally, students need to be engaged in learning experiences (Damoense, 2003). To be engaging, experiences need to be relevant and to incorporate and model teaching strategies that keep learners interested and learning.

\section{Webfolio}

The Webfolio project was designed to address these issues of integration, relevance and collaboration. It was an online learning environment, where education students, and education related professionals such as lecturers, teachers, principals, social workers, guidance officers, community participation officers, lawyers and police officers interacted with each other and accessed virtual resources to explore topics of significance to the developing and practicing educational professional. Baskin and Anderson (2003) note that online units "enable interactions that promote a sense of belonging to a wider and richer learning environment than the immediate classroom" (p. 4).

Webfolio assumed a Webquest format, in that it was an inquiry oriented activity where introductory information about the task, the task itself and the processes to follow were presented to the learner. Local, online resources and information were offered, but some of the information learners needed also came from external, Internet resources (Damoense, 2003). The project aimed to extend students' professional learning through topics that integrated a number of different learning areas. Topics were chosen by surveying students, university staff and practising teachers about areas of professional significance that teachers may encounter in their day to day work, but that may need more attention within the university program. In this trial, the five topics chosen were: child protection, ethics, partnerships, bullying and brain development. For each topic, a case scenario was written that presented a problem to be solved. Some support material was offered for each case scenario, such as audio plays, factual information, personal anecdotes and samples of children's work. Links to topical websites were also included. Each topic also had two professional contacts attached to it. These were professionals with particular expertise in one field, who were available for individual students or groups to consult to further clarify an issue. For example, the two professional contacts for the child protection scenario were social workers from a behaviour support team within the state education department.

Webfolio targeted generic skills identified by the university and the teaching profession, and these skills were used in the process of working through the case studies. Three main areas of generic skills chosen were: group work, problem solving and communication. Group work included learning experiences where participants question and share knowledge (Queensland Government, 2001) and participate in learning communities 
that characterise ethical professional practice (Queensland Board of Teacher Registration, 2002). Problem solving included implementing critical thinking, analysis, evaluation, and reasoning to define and solve problems (James Cook University, 2002), and communication included establishing connections with the world beyond the classroom (Queensland Government, 2001), and using a variety of media and a range of literacies to communicate ideas and information relevant to professional roles (James Cook University, 2002; Queensland Board of Teacher Registration, 2002).

Participants explored each case for three weeks, in the context of a learning community that incorporated interaction with the whole group, a smaller sub-group, one to one, and individual exploration of topics. In the first week, participants read and engaged with the case study, investigated the information provided, and, in sub-groups begin online discussion of the topic. If they needed specific information or guidance that was not available online or through the discussions, they were able to get help from professional contacts by email or in real time.

In the second week of the case scenario, participants worked in their subgroups toward further understanding of the case, including coming to a consensus of opinion and generating options for action, which could be shared by the larger group. By the third week, a summary of each group's discussion and options for action were posted on a whole group discussion board for further discussion and development of options.

Following this process, participants were asked to reflect on ideas presented and to determine their own options for action in similar situations. These choices, and the processes through which they were developed, were then be documented in the Webfolio Skills Assessment, a document that could be used in hard copy or electronically as a component of a portfolio to be presented in interviews and referred to when faced with similar situations in the future.

Following completion of the five case study trial, student participants were asked to complete an online survey about the project. Professional participants were invited to provide anecdotal feedback as well. Based on this feedback, changes to Webfolio will be undertaken to refine it for use in student learning and professional development.

\section{Theoretical framework}

The Webfolio project was based on engagement theory, where authentic tasks or problems are presented to learners, who must then construct, interact and collaborate with others to solve the problems (Damoense, 
2003). Instruction was interactive, in that instructors and participants learned together as they explored topics; and generative, in that learners engaged, thought deeply, collaborated, made decisions and created options for solving the problem. Particularly suitable to online learning, engagement theory encourages the establishment of collaborative learning teams, taking a project based approach, where a task or problem provides a vehicle for learning, and designing an authentic leaning environment with authentic tasks, where the learner is engaged in real world problems or challenges that are related to their interests (Damoense, 2003).

\section{Collaborative learning}

Collaborative learning is important not only as a way of creating authentic and deep learning (Herrington, Oliver \& Reeves, 2003), but also as a way of modelling an approach to learning that can then be applied to classroom practice. Kluth and Straut (2003, p. 16) note: "Teachers need the opportunity to practice and learn about shared decision making, communication and planning." Webfolio focused on collaborative learning through online and real time discussion between students, professional participants, and professional contacts.

Collaboration began when student participants were divided into three sub-groups: Lavender, Amethyst and Lilac. Professional participants had access to all three groups. After individual reading and examination of the case scenario and supporting evidence, each of the three sub-groups engaged in online discussion about the problem and attempted to arrive at a consensus of options for action. These options were then posted on a whole group discussion board and all participants were encouraged to comment on each sub-group's ideas.

Using a variety of collaborative processes allows participants to contribute in different ways to their own and others' learning. Through belonging to an online learning community, participants "contribute in a variety of inter-dependent ways to the purpose of the community and engage with others around that purpose" (Baskin \& Anderson, 2003, p. 4).

\section{Problem based and project based learning}

Problem based learning comes from a view that all knowledge is constructed and reshaped through social, political and cultural influences (Education Queensland, 2002). Too often, what is taught in teacher education is not presented as problem based and with links to the real world. Students tend to expect, and often receive, "correct" solutions to specific situations (Sorin \& Klein, 2002). However, keeping in line with authentic, real world situations, Webfolio problems were purposely ill- 
defined, not easily solved and open to multiple interpretations (Herrington, Oliver \& Reeves, 2003). Some details were written into the case scenario; others were presented through short audio plays that offered a glimpse into the situation. The rest was left to the learner to explore and support with information obtained from a number of sources, including website links, information included with the scenario, and information from others. Organising learning around loosely structured problems encourages learners to work through them, drawing upon and developing skills and knowledge related to a number of disciplines (Borich, 2000).

\section{Authentic learning}

Collaboration in problem based learning will not be successful without authenticity. Authentic learning is based on real world problems that have meaning to the learner (Herrington, Oliver and Reeves, 2003). "A virtual learning environment must be able to offer meaningful forms of membership, or it will simply reproduce the personalities, communities and economies of meaning that already exist outside it" (Baskin \& Anderson, 2003, p.5). But to be meaningful, the learning environment does not have to be based on what the learners already know; it can be based on the world towards which the learner is progressing. Hesitant learners may need to "suspend disbelief" as they give themselves over to the context of the learning situation. Likening this process to what audiences must undergo to become engaged with movies such as Star Wars and The Matrix, Herrington, Oliver and Reeves (2003, p. 61) suggest that "it is often only when the suspension of disbelief occurs that these students see the complexity and the value of the learning environment."

Webfolio offered participants real world problems that were based on experiences of practising teachers and educational professionals. For example, the child protection scenario was developed from a variety of experiences of teachers and social workers. It incorporated details such as glimpses of the child and her family, observations by the teacher and her colleagues, and a conversation between the teacher and the child. The scenario was supplemented by anecdotes from teachers, principals and a school nurse about their experiences in child protection; samples of children's artwork and writing that indicate abuse, and statistics relevant to the Queensland area. Student participants expressed their surprise at the scope of situations they will face as teachers. Susan, a third year student, said, "Until reading the case scenario, I had not really considered the enormity of what we will be expected to deal with when we are out there teaching!" 
Benefits of authentic activities in online learning environments include the creation of a contextualised, practical learning environment where students are encouraged and motivated to solve problems through applying theoretical and practical perspectives to realistic situations (Herrington, Oliver and Reeves, 2003). They also allow learners to investigate, make diverse choices and reflect upon their learning over a period of time, and integrate disparate subject areas and outcomes (Herrington, Oliver and Reeves, 2003). Ironically, frustration with authentic learning can be the result of these tasks being so similar to "the kind of uncertain and messy tasks that people are often required to do in their professional lives" (Herrington, Oliver and Reeves, 2003, p. 68).

\section{Redefining the roles of teacher and learner}

Traditionally, teachers have been positioned as instructors, who teach learners what to do to become effective. Learners have been positioned as passive recipients who take in knowledge from the instruction as well as from print resources such as textbooks (Damoense, 2003). Online learning based on engagement theory repositions teachers as facilitators, who interact and collaborate with learners who are active, engaged and empowered. "The essential impact of student interaction with online learning environments is an emerging learner control over the experience" (Baskin, 2001, in Baskin and Anderson, 2003, p.3).

Resources in online learning move away from the traditional, print based ones to innovative, web based resources such as Webquest. Nonetheless, engagement with the learning is essential. Baskin and Anderson (2003, p. 1) caution: "Teaching in an online environment still requires an ability to generate enough excitement, energy, relevance and value to attract and engage members."

\section{Webfolio outcomes}

The Webfolio trial ran from early June until the first week of October, 2003. During this time, enthusiasm waned for a number of participants. Many students cited time difficulties with this project, as they were participating in Webfolio while studying a full load of subjects at university. One student said, "I found I didn't have the time to participate. Due to it being outside of a subject, my priorities were to my uni subjects first and that left me with little motivation or time." Another said, "I was really interested in the topics presented, but found that just keeping up with my uni subjects was taking enough of my time." However, of the 21 students who began the project, 15 completed a minimum of three case studies. Three others contributed to discussions and four did not contribute. 
Professionals' participation was somewhat more disappointing. Of the 16 professionals who agreed to participate in the project, only two participated in three or more case studies and, while many reported that they had read and followed the discussions, only five actually contributed to the discussions. A few professionals cited technical problems as the reason, such as computer breakdowns and unfamiliarity with online procedures. Others mentioned the time factor, and still others felt that they were not expert enough in some fields and might be "intruding" in areas beyond their fields of expertise.

Following its completion, participants were surveyed about the site and their experiences. Student participants were asked to complete an online survey, which was accessed from the Announcements page of the Webfolio site, that included multiple choice questions and opportunities to elaborate anecdotally on various issues of Webfolio. Professional participants were asked to give feedback about the project either through email, by telephone or in person. Feedback from all participants was encouraged, whether or not they had contributed substantially to online discussions.

Of the 21 students, 16 completed the survey. One of these had difficulties online, so shared her thoughts with me through an email. This sample included 13 who finished the project with participation in a minimum of three and maximum of five case studies and three who participated in one to three case studies.

The majority of students agreed strongly that the content of the case studies was relevant to their professional development. One student commented: "I was pleased with the variety of scenarios posed and felt that it was both broad and relevant, very worthwhile taking the time to sit and think." For the most part, participants found the content interesting and the amount of information given, sufficient. However, one student felt that not enough information was given in the scenarios:

It was difficult to think hypothetically about ethical issues when we did not have the whole picture of what was going on in the scenarios. For example the father who wanted to speak about the child - there were so many questions that if we were actually in this situation we could make a judgment about, but by being removed it made it difficult to really make any informed decision.

This suggestion was refuted by professional participants, who said that in real life situations you are often working with very little information, and it is up to you as a teacher to "put the pieces together" to make informed and ethical decisions for the benefit of the child. 
There was less agreement about the inclusion of professional participants. Twenty percent of responses disagreed that the professionals enhanced their learning experiences, and another 7\% neither agreed nor disagreed. One student said, "It was wonderful having people in the field contributing and getting ideas and comments from those who are out there doing it." Another, however, commented that it was "disappointing that the professionals did not become more involved to put us on the right track at times." Another said, "Professional participants rarely contributed, if at all...I believe I would have benefited from them had they had more to say."

The benefits of learning in a community of learners were acknowledged by most students, with $86 \%$ agreeing or strongly agreeing with this and the remaining 13\% neither agreeing nor disagreeing. Comments included:

The aspect I enjoyed most was communicating with other students in the teaching profession. Being able to have a discussion with others allowed me to see other points of view and get insights from other professionals.

Having online interaction with, and access to other participants' opinions is extremely valuable and an efficient way to communicate. I think it is really important to be continually interacting with colleagues/ peers /

professionals. I know that on prac, when you desperately would like to discuss certain issues or ask certain questions that may arise throughout the school day, it is not possible because everyone is too busy. So accessing professionals online is a real privilege.

Discussing the various situations online with my colleagues was on the whole a great learning experience. It accentuated the benefits of discussing problems to find the best possible range of solutions. A key element of teaching practice, I believe - discussion, collegiality and looking at a situation or problem from different perspectives.

Webfolio certainly broadened my network within the uni and several schools I approached to converse with principals.

However, a few students felt that their comments weren't valued by others. One wrote:

I may be too sensitive for my own good, but I felt that I was being judged/ put down by a couple of the participants, which put me off expressing myself honestly. I would have preferred it if the thing was anonymous, because a couple of the reactions / responses I got I felt that I was being judged...I think that some of the participants tended to say things / not say things based on their political correctness. I feel that anonymity would produce more honest responses.

Other participants suggested that the discussion format allow anonymous comments, a feature of the technological format that can be enabled. 
While students agreed that they were supported by Webfolio facilitators, who joined in discussions at times, to present contradictory arguments to broaden the conversation, one commented that more could have been done: "I believe the online conversations could have been enhanced if the facilitators had participated more." A suggestion was to have "face to face group discussion to further propel the issues raised." This was also suggested by some of the professional participants, who indicated an interest in meeting students face to face to further their discussions.

A number of students commented on the waning interest at times apparent in the sub-group discussions. One student said, "I observed other groups with what appeared to be a lot of good interaction and our group ended up with about 3 of us participating, which was quite disappointing." It was suggested that two sub-groups of 10 and 11 might have worked better than three groups of 7 , considering the dropout rate in some of the discussions. A suggestion was:

Maybe next time, let everyone be in one big group, more conversation perhaps, but for those of us in a group with little participation, it would have been better. I was envious reading some of the comments from other groups, that showed that a lot of participation and interactions had occurred.

The technology based focus of the Webfolio project was lauded for allowing participants to interact with the scenario and others after considered reflection, and in their own time. It was also a way for students who are less vocal in class to actively participate. Comments included:

Technology based learning affords me time to consider my reactions to authentic and relevant situations I may encounter in my career. I feel better prepared in terms of knowing how to access resources, human and otherwise, to solve possible problems / challenges.

I like the format of Webfolio, the constant access allowed me to choose times that suited me, which was great.

Having the freedom to participate in my own time was great. I could access the information and then think about my response.

I love using computers and really benefited from this form of communication, especially when I was able to think about my replies and not be put on the spot, like in a tutorial situation...Those who feel intimidated to participate in tutes because of shyness can freely participate online.

Although all found the site to be quite user friendly, fourteen percent of respondents felt either neutral, or disagreed that working online enhanced their learning experience. One student suggested a need for further 
explanations of online procedures: "As yet I have not made a portfolio of my contributions as I'm not sure how to do this." Another appreciated the opportunity to expand his/her technological knowledge: "Learning to navigate is good as we will soon be out there with a lot of technology."

There was a great variance in opinion about the benefit of situating the Webfolio project outside of a university subject. Forty-six percent agreed or strongly agreed that this beneficial. One student said:

Because it was not attached to a subject, I felt free to just play around with ideas more. When I wanted to ponder over an issue, it gave me the freedom to do that, again fitting into my routine and allowing time to participate at my own pace and level.

Another $40 \%$ neither agreed nor disagreed and a further 14\% disagreed. One student explained: "I found I didn't have the time to participate. Due to it being outside of a subject, my priorities were to my uni subjects first, and that left me with little motivation or time."

The issue of time was noted by a number of participants, both students and professionals. One commented:

Time seemed to be a big problem for a lot of people sadly. Maybe break up the study over two time frames, at the beginning of each semester, and even before semester starts, to introduce people to the idea. But there will always

be people that have situations that do not allow them to participate.

A number of professional and student participant suggested that Webfolio would be better situated within a university subject, as part of subject assessment. The lack of participation by many of the professionals elicited these comments from students:

I would have liked more of the professional people to get more involved in the discussions with students. But you can't force them to participate so perhaps looking at engaging them more fully would be beneficial. When they did participate, they had valuable insights to share with us.

It was further suggested that possible credit be given to professional participants who might be undertaking a graduate degree, or an honorarium be given to them for their participation.

While most students agreed or were neutral about the creation of portfolios as preparation for job interviews and future careers, $7 \%$ of students strongly disagreed with this. This might indicate a need for further development of the technology, both within the university to support an electronic portfolio, and by teaching students how to create one. 
For the most part, participants agreed that generic skills were developed or enhanced in the Webfolio project. "It was a great opportunity to bring all of our skills together and collaboratively try them out, so to speak. We could test our knowledge from our university degree so far, and bring ideas to the table (computer)." However, some issues of group work and communication skills, involving interaction with others, particularly with professional participants, drew some disagreement from students. One commented: "Due to lack of participation by many people (including myself) the conversations lacked body and texture."

\section{Conclusion}

While most students and professionals reported that they enjoyed and benefited from the Webfolio project, the suggestions they have made will help to further develop and direct the project. These include: a trial of embedding the project as an assessable item in a university subject; more incentive for professionals to participate; informal, face to face sessions between students and professionals, to discuss and debrief case studies; face to face technology assistance and role clarification for professional participants, where needed; and further development of how to use the processes and products of the case studies in portfolios.

\section{References}

Baskin, C. and Anderson, N. (2003). The on-line classroom: a self-actualising theme park or trial by multi-media? Australian Educational Computing. 18 (1), 11-20.

http: / / www.acce.edu.au/journal/journals/vol18_1.pdf [verified 21 Mar 2004]

Borich, G. (2000). Effective Teaching Methods. 4th ed. Upper Saddle River, New Jersey: Prentice Hall.

Damoense, M. Y. (2003). Online learning: Implications for effective learning for higher education in South Africa. Australian Journal of Educational Technology, 19(1), 25-45. http:/ / www.ascilite.org.au/ajet/ ajet19/damoense.html

Herrington, J., Oliver, R. and Reeves, T.C. (2003). Patterns of engagement in authentic online learning environments. Australian Journal of Educational Technology. 19(1), 59-71.

http:/ / www.ascilite.org.au/ajet/ajet19/herrington.html

James Cook University School of Education (2002). Generic skills for graduates of Bachelor's degrees and coursework Postgraduate degrees. [accessed 2002 at http:/ / www.faess.jcu.edu.au/ soe/gradquals.html; revised version verified 25 Feb 2004 at

http:// www.faess.jcu.edu.au/soe/undergraduate/graduate_qualities.html] 
Kluth, P. and Straut, D. (2003). Do as we say and as we do: Teaching and modelling collaborative practice in the university classroom. Journal of Teacher Education. 54(3), 228-240.

Lave, J. and Wenger, E. (1991). Situated learning-legitimate peripheral participation. Melbourne: Cambridge University Press.

Queensland Government (2001). Professional Standards for Teaching - guidelines for professional practice. Brisbane: Education Queensland. [verified 21 Mar 2004] http:/ / education.qld.gov.au/staff/learning/standards/teachers/ resources /

Queensland Board of Teacher Registration (2002). Professional standards for graduates and guidelines for preservice teacher education programs. [verified 21 Mar 2004] http:/ / www.btr.qld.edu.au/pdf/standard.pdf

Sorin, R. (2002). Bridging the Gap - the impact of a preservice teachers' network on the developing Early Childhood teacher. In J. Reid and T. Brown (Eds),

Challenging Futures: Changing Agendas in Teacher Education. Challenging Futures conference, Armidale NSW, February.

http: / / scs.une.edu.au/CF/Papers/Sorin.htm

Sorin, R. and Klein, M. (2002). Walking the walk and talking the talk: Adequate teacher preparation in these uncertain times? AARE 2002 Conference Papers, Brisbane,1-5 December. http://www.aare.edu.au/02pap/sor02045.htm [verified 21 Mar 2004]

\section{Dr Reesa Sorin}

Coordinator of Early Childhood Education/ Coordinator of the Arts

School of Education, James Cook University

PO Box 6811, Cairns Queensland 4870, Australia

Email: Reesa.Sorin@jcu.edu.au

http:// www.faess.jcu.edu.au/soe/staff/ reesa.sorin.html 